\title{
O PROCESSO DE URBANIZAÇÃO DA AMAZÔNIA E SEUS MECANISMOS ENTRE A DÉCADA DE 1930 E 1980
}

\section{THE PROCESS OF URBANIZATION OF THE AMAZON AND ITS MECHANISMS BETWEEN 1930 AND 1980}

\section{EL PROCESO DE URBANIZACIÓN DE LA AMAZONIA Y SUS MECANISMOS ENTRE LOS AÑOS 1930 Y 1980}

\author{
Claudia Pinheiro Nascimento \\ Mestre em Geografia pela Universidade Federal de Rondônia \\ nascimento.cp@gmail.com
}

\section{Resumo}

A construção do espaço amazônico apresentou diferentes elementos na sua constituição ao longo de sua história, prevalecendo sempre a busca pelas riquezas naturais. Os mecanismos e políticas de ocupação agruparam-se de forma diferenciada em cada momento histórico, apresentando realidades específicas dentro do processo de urbanização da Amazônia, entre as décadas de 1930 e 1980. Dentro deste contexto, fazse necessário o entendimento dos mecanismos internos e externos responsáveis pela dinâmica do espaço urbano amazônico, para que se consiga obter um entendimento mais amplo de todo o processo histórico e da sua influência na construção do espaço urbano atual. Este artigo busca fazer uma reflexão ao longo de suas páginas acerca do entendimento histórico da ocupação na Amazônia, as políticas implantadas, a formação e transformação dos espaços urbanos.

Palavras-Chave: Amazônia, Ocupação, Mecanismos internos e externos.

\begin{abstract}
The construction of the geographical space of Amazonian region implied different elements in its constitution throughout its history, always concerning the search for natural resources. The mechanisms and policies of occupation came together under different issues at each historical moment, creating specific circumstances accountable for the Amazonian urbanization between 1930 and 1980. Within this context, it turns out necessary to grasping the internal as well as the external mechanisms responsible for the urban space dynamics of Amazon. In order to have a broader understanding of all historical process and its influence on the current urban space construction, this article focuses on a clear understanding of the Amazon's settlement history, the policies implemented and the information and changes of the urban space.
\end{abstract}

Keywords: Amazon, Occupation, Internal and External Mechanisms. 


\section{Resumen}

La construcción del espacio amazónico presentó elementos diferentes en su constitución a lo largo de su historia, predominando siempre la búsqueda por sus recursos naturales. Los mecanismos y las políticas de ocupación se han agrupado de forma diferente en cada momento histórico, revelando circunstancias específicas responsables por la urbanización en la Amazonia entre los años 1930 y 1980. En este contexto, es necesario comprender los mecanismos responsables por la dinámica interna y externa del espacio urbano en la Amazonia de forma que se pueda obtener una comprensión más amplia de todo el proceso histórico y su influencia en la construcción del espacio urbano. En este artículo, se pretende hacer una reflexión sobre el conocimiento de la historia de la ocupación en la Amazonia, las políticas implantadas, la formación y transformación de los espacios urbanos.

Palabras Clave: Amazonia, Ocupación, Mecanismos Internos y Externos.

\section{Introdução}

O estudo tem como base o período entre as décadas de 1930 e 1980, pela condição assumida pelas cidades amazônicas neste momento, que passam a se localizar e concentrar seu povoamento ao longo dos eixos rodoviários, além dos tradicionais eixos de circulação fluvial. Este processo esteve associado à inserção do Brasil no capitalismo global, após a Segunda Guerra Mundial, quando se iniciou a integração efetiva da Amazônia ao capitalismo nacional, tanto física, com a construção das estradas, quanto política e economicamente, através da intervenção direta do Estado Nacional, com a implantação dos planos econômicos e dos órgãos governamentais de regulação.

A sociedade amazônica tradicional ribeirinha, que apresentava os rios como forma de organização das suas cidades, passa a um novo padrão de ocupação do seu espaço com a construção de centenas de quilômetros de estradas, no início da segunda metade do século XX (SÉRRE, 2001).

Segundo Browder e Godfrey (1997), a análise do povoamento da Amazônia é um processo complexo e múltiplo que requer atenção aos elementos envolvidos. Essa complexidade da Amazônia brasileira manifesta-se tanto no quadro natural quanto humano, que, segundo Gonçalves (2001), ocorre porque a Amazônia é, sobretudo, diversidade. 
Dentro deste contexto, utilizou-se o conceito de Formação Sócio Espacial ${ }^{1}$, como ferramenta de análise da organização do espaço urbano amazônico.

O conceito de Formação Sócio Espacial considera o fato de que, a cada momento histórico, os elementos mudam seu papel e a sua posição no sistema temporal e no sistema espacial, e que, em cada um destes momentos, o valor de cada um dos elementos deve ser tomado levando-se em consideração a sua relação com os demais elementos e com o todo (SANTOS, 1982).

Valorizou-se, neste sentido, os elementos econômicos, sociais, políticos e os movimentos migratórios que participaram da formação do espaço, além do planejamento estatal capitalista, que avançou sobre a Amazônia a partir de meados da década de 1960.

Metodologicamente, buscou-se um levantamento e leitura de referências bibliográficas que trabalham o assunto sobre diversas óticas com o intuito de reconstruir teoricamente, de forma mais próxima da realidade, como se deu o processo de urbanização da Amazônia durante as décadas de 1930 a 1980.

Didaticamente, a reflexão está dividida em duas partes principais: a primeira parte destaca o processo histórico de ocupação da Amazônia e os elementos responsáveis pela construção e organização do espaço amazônico até o início do século XX. A segunda considera especificamente o processo de urbanização da Amazônia, dentro dos mecanismos externos e internos de incorporação da região.

\section{Histórico da Ocupação da Amazônia}

A conquista e a colonização da região Amazônica foram motivadas por diversos fatores, prevalecendo sempre a busca de riquezas minerais, vegetais e a consolidação de uma base de produção mercantilista que garantisse lucros imediatos à metrópole

\footnotetext{
${ }^{1}$ O conceito de Formação Sócio Espacial foi desenvolvido por Milton Santos e surgiu a partir da publicação do artigo "Society and Space: Social Formation as Theory and Method" na revista Antipode em fevereiro de 1977. No ano de 1979 tornou-se capítulo do livro Espaço e Sociedade, publicado pela editora Vozes. O conceito de formação Econômica Social e Espacial surge como uma nova forma auxiliar a leitura e interpretação do espaço. Esta categoria diz respeito a evolução diferencial das sociedades, no seu quadro próprio e em relação as forças externas. A própria base para a explicação é a produção, o trabalho do homem para transformação, segundo leis historicamente determinadas. Dentro deste contexto entram também as especificidades sociais, políticas e econômicas que compuseram esse processo de formação espacial.
} 
(NASCIMENTO, 2009). Os Espanhóis foram os descobridores do vale amazônico, porém a ocupação e a colonização ficaram a cargo de Portugal.

O cenário internacional foi o que incentivou essas conquistas, a expansão mercantilista européia iniciada no séc. XV, que necessitava incorporar novas áreas ao sistema emergente capitalista. Neste cenário, uma das alternativas encontradas foi o continente americano, e entre os países americanos daremos ênfase ao Brasil (NASCIMENTO, 2009).

Segundo Teixeira e Fonseca (2002), o primeiro núcleo colonial português estabeleceu-se na Amazônia no início do séc. XVII, o forte do presépio, que daria origem a Belém do Pará. O interesse na construção do forte estava na posse do território ameaçado pelos estrangeiros que ali estabeleceram feitorias.

A cidade de Belém, capital paraense, seguiu o padrão de criação urbana que antecedeu ao povoamento de suas futuras regiões de influência. A capital foi fundada pelos portugueses provenientes de São Luís e tinha como função servir de ponto estratégico para a proteção da região contra ataques de estrangeiros (TEIXEIRA e FONSECA, 2002).

Francisco Castelo Branco funda, em 1616, o Forte do Presépio, de onde se desenvolve a cidade de Belém. Foi do pequeno núcleo, junto ao forte, que surgiram os primeiros núcleos de povoamento como as atuais cidades de Bragança, criada em 1633 e Cametá, criada em 1635 (PRATES, 2008).

Segundo Corrêa (1987), este seria o primeiro período do estabelecimento da rede urbana amazônica, onde as cidades apresentavam duas funções: a primeira, de servir como ponto de defesa do território; e a segunda, a de servir como ponto de penetração e conquista do território. Esse padrão de elaboração da rede urbana foi também o aplicado em muitos países da Ásia, África e do continente Americano.

O interesse de ocupação das áreas amazônicas ocorria em uma parceria dos colonos com o governo português, que visavam dominar a região dada a sua exuberância e vastidão. Outro fator que impulsionou Portugal foi o interesse de organizar, após 1655, o mercado de especiarias, por eles denominados no Brasil como "Drogas do Sertão" (TOCANTINS, 1960).

A partir de 1655, devido à perda do mercado produtor de especiarias com o Oriente, a Europa centra-se na procura, coleta e comércio de especiarias, implantando 
na região amazônica a exploração das chamadas "drogas do sertão" produtos valorizados na Europa, utilizados como condimentos, em uso farmacêutico, enfeites e englobava produtos como o cacau, cravo, canela, salsaparrilha, madeira, manteiga de peixe, entre outros (TOCANTINS, 1960). Este período estende-se da metade do séc.XVII ao final da primeira metade do séc. XVIII, correspondendo, segundo Corrêa (1987), à segunda fase da elaboração da rede urbana da Amazônia.

Foram as missões religiosas as responsáveis pelo maior impulso de civilização na Amazônia. Primeiramente, vieram os franciscanos, que levantaram o convento da Una, depois os Jesuítas, Carmelitas, Mercedários, Capuchos da Piedade e os frades da Conceição da Beira do Ninho (TOCANTINS, 1960).

Segundo Tocantins (1960), a carta Régia de 1693 estabeleceu zonas de influência para as ordens pias. Na margem meridional do Amazonas, ficaram os jesuítas, na região do cabo norte, os frades capuchos de Santo Antônio e na margem setentrional do rio mar, cabendo o distrito de Gurupá aos padres da piedade.

O trabalho missionário estava ligado ao trabalho social e econômico da Amazônia, foi o que permitiu romper as organizações indígenas, ativar a agricultura e agrupá-las nas aldeias, formando células de povoamento regional, de onde nasceram quase todas as cidades sedes dos municípios atuais (TOCANTINS, 1960). Foram as aldeias missionárias que desempenharam o papel de estabilizador social e de centros de expansão da colonização.

Em meados do séc. XVIII, o controle territorial missionário foi rompido, em função da descoberta das minas de ouro, pelos conflitos entre colonos e missionários, pelo controle da mão-de-obra indígena, além da crise em Portugal, que inicia um processo de reforma político-econômica instaurando a era pombalina.

Inicia-se, então, a terceira etapa da periodização da Amazônia exposto por Corrêa (1987), em que o relativo desenvolvimento urbano da Amazônia estava totalmente apoiado na Ação da Companhia Geral do Grão Pará e Maranhão, fundada em 1755 sob o domínio do Marquês de Pombal, primeiro ministro português.

Durante o período de 1750 a 1780, a rede urbana amazônica, até então embrionária, passa por um desenvolvimento mais profundo, que não derivou da incorporação de novas áreas à economia colonial e o conseqüente aparecimento de novos núcleos dotados de funções urbanas, derivou principalmente da expansão das 
atividades produtivas nas áreas já incorporadas economicamente (CORRÊA, 1987). A era pombalina institui, então, mudanças no contexto da Amazônia através da construção de novas unidades administrativas, na construção de fortificações mais eficientes, na transformação dos antigos núcleos missionários em vilas portuguesas e com expedições científicas demarcatórias que criaram um acervo regional e cartográfico.

A empresa pombalina foi a responsável por mudanças específicas dos elementos da rede urbana amazônica, assim como também fez acentuar tantas outras funções urbanas. A paisagem urbana amazônica caracterizava-se como uma réplica parcial da paisagem urbana portuguesa (CORRÊA, 1987).

O final do séc. XVIII e a primeira metade do séc. XIX seriam marcados por uma estagnação econômica e urbana regional na qual, segundo Corrêa (1987), compreende o quarto período de expansão da rede urbana amazônica. Dois fenômenos externos na Amazônia aparecem como os responsáveis pela estagnação econômica e urbana, a extinção, em 1778 da Companhia Geral do Grão Pará e Maranhão e o desfavorecimento dos produtos tropicais, em geral, no panorama mundial (CORRÊA, 1987, p.47).

Ambos os eventos afetaram a vida urbana, que não mais se caracterizava como embrionária, mas ainda não era solidamente estabelecida. Verifica-se, de um lado, a paralisação da expansão agrícola nas áreas de produção mais importantes e, do outro, como conseqüência, uma diminuição do crescimento urbano, chegando a causar a diminuição da população urbana (CORRÊA, 1987, p.47).

Ao final da primeira metade do séc. XIX, em um momento antecedente à grande expansão econômica e urbana apoiada na valorização da borracha, a rede urbana amazônica caracteriza-se pela ascensão de Belém, e por um padrão espacialmente ribeirinho, centrado no eixo do rio Amazonas.

Entre os anos de 1850 e 1920, temos o quinto período de expansão da rede urbana amazônica segundo Corrêa (1987). Neste período, a rede urbana amazônica ganha nova dimensão em termos econômicos e espaciais, tendo como pano de fundo o boom do extrativismo da borracha.

Segundo Corrêa (1987), as condições que permitiram a expansão do extrativismo da borracha foram: primeiramente, a crescente demanda da borracha no mercado internacional e, depois, a superação de dois obstáculos regionais, o primitivo sistema de 
transportes e a falta de mão-de-obra além de capitais disponíveis para o financiamento da produção.

A partir de meados do séc. XIX, a exploração e exportação da borracha, que acontecia de forma incipiente, aumentam em função do crescimento da produção em novas áreas extrativistas. Esse período foi denominado de "primeiro ciclo da borracha", que durou de 1877 a aproximadamente 1912.

\begin{abstract}
"Acompanhando, passo a passo, os índices da exportação da borracha, verifica-se o crescimento irresistível de números, significativo da demanda cada vez maior. Em 1847-1848, exportaram-se 58.367 arrobas. Em 18591860, 170.532 arrobas. Sete anos adiante as arrobas subiram para 412.384. E quando. Em 1871, o presidente Abil Graça dirigiu-se a Assembléia Legislativa da província, já anunciava que a borracha alcançara o primeiro lugar nos gêneros de exportação. Goma elástica, 4.890 .089 quilos, cacau 3.381.246 quilos" (TOCANTINS, 1960, p.160).
\end{abstract}

Mesmo com as crises nos preços em 1900 e 1908, a extração da borracha apresentou uma ascensão incrível, apresentando em 1911 o máximo da produção, ver tabela 1.0.

Tabela 1.0 - Produção da Borracha entre os anos de 1901 a 1911

\begin{tabular}{|c|c|}
\hline Período & Produção (em Toneladas) \\
\hline 1901 & 29.971 \\
\hline 1902 & 29.890 \\
\hline 1903 & 32.590 \\
\hline 1904 & 33.090 \\
\hline 1905 & 34.680 \\
\hline 1906 & 37.540 \\
\hline 1907 & 36.650 \\
\hline 1908 & 38.511 \\
\hline 1909 & 39.494 \\
\hline 1910 & 38.177 \\
\hline 1911 & 44.290 \\
\hline
\end{tabular}

Fonte: Tocantins, (1960, p. 179)

Juntamente com o crescimento da exportação da borracha no mercado internacional, surgiu a necessidade crescente de mão-de-obra, que foi resolvida, em parte inicialmente, pela imigração intra-regional. 
Migraram para as novas áreas extrativistas do oeste amazônico as populações dos antigos núcleos de colonização, porém essa mão-de-obra não foi suficiente, permanecendo a exploração da mão-de-obra indígena. A mão-de-obra nordestina utilizada desde as primeiras décadas do séc. XIX foi uma das alternativas, porém, intensificou-se com o aumento da demanda de matéria-prima e com a pior seca do século ocorrida no Nordeste do Brasil (1879/80).

Segundo Ianni (1979), foi a grande seca no Ceará que propiciou condições para a vinda da mão-de-obra nordestina para os seringais, cerca de 60.000 nordestinos já haviam penetrado nos seringais acreanos em 1900. Os efeitos estavam associados à expansão da própria rede urbana e ao revigoramento econômico e demográfico dos núcleos urbanos já existentes, assim como a intensificação das relações entre os núcleos de povoamento, via mecanismos de "aviamento".

O processo de expansão do extrativismo da borracha ultrapassou os trechos encachoeirados e de corredeiras dos afluentes do rio Amazonas, através das construções de ferrovias, um dos exemplos é a expansão que ocorreu pelo alto vale do rio Madeira. A economia da borracha iniciou o desenvolvimento da urbanização, definindo o surgimento de novas aglomerações e o desenvolvimento inicial da forma urbana, reflexo da hierarquia imposta pelo comércio da borracha. Belém e Manaus se destacam com a evolução da economia da borracha, a primeira, pela descentralização dos recursos financeiros e pela população, a segunda, pela interiorização das frentes exploradoras da borracha (CORRÊA, 1987).

\footnotetext{
"Trata-se na realidade, de uma primeira mudança na natureza da rede urbana, envolvendo as seguintes modificações: gênese dos núcleos urbanos, fruto da colonização oficial; dependência a produtos destinados ao mercado regional e não para exportação; sítio em terra firme e não em um terraço fluvial; localização a beira de uma ferrovia e não de rios que convergiam para Belém. Mas estas mudanças que associam ao processo de criação da zona de maior densidade urbana da Amazônia, constituem-se em um subproduto da expansão da borracha em seu momento de máxima valorização. Não caracteriza, por isso, nenhuma fase específica do processo de elaboração da rede urbana. Mas vários dos aspectos caracterizam esse setor da rede urbana amazônica irão caracterizar vários segmentos da rede urbana amazônica nos períodos pós - 1960" (CORRÊA, 1987, p.51).
}

Entre os anos de 1911 a 1920, a produção da borracha na Ásia já havia ultrapassado a produção brasileira. 
“A Ásia possuía já em 1920 cerca de 1.700 mil hectares de terras cultivadas com seringueiras, cujo número era superior a 300 milhões de pés" (SANTOS, 1980, p.44).

A partir de 1910, quando os preços começaram a cair no mercado internacional, numerosas casas "aviadoras" passam a falir, havendo paralelamente o abandono de seringais, a diminuição do tráfego fluvial, desempregos urbanos e nos seringais, além do aumento da dívida pública interna e externa. Inicia-se então o sexto período determinado por Corrêa (1987) como a fase da estagnação decorrente da crise da borracha no mercado internacional.

Com o intuito de manter elevados os preços da borracha e a posição do Brasil no mercado internacional, em virtude do contrabando de mudas de seringueira para o Oriente pelos Ingleses, foram tomadas algumas medidas embora tardiamente. Sendo assim, em 1911 foi criada a Liga dos Aviadores, um órgão de classe que visava proteger os interesses mercantis regionais (TOCANTINS, 1960). Ainda em 1911, cria-se o convênio Pará-Amazonas que, na esfera oficial, visava defender os interesses vinculados ao comércio da borracha.

Em 1912, o governo federal cria o plano de Defesa da Borracha, um projeto de desenvolvimento regional envolvendo a produção da borracha, industrialização, imigração, saúde, transportes e produção agrícola. Contudo, nenhum dos planos conseguiu cumprir seu papel objetivamente. A estagnação da borracha traz uma nova configuração espacial para a região, diminui o fluxo migratório para a Amazônia, mas também inicia um refluxo da população para suas áreas de origem (PRATES, 2008).

Tendo em vista a tendência dos seringalistas de se libertarem do comércio de Belém e Manaus, os centros responsáveis pelo abastecimento de gêneros alimentícios, foi permitido o desenvolvimento da agricultura de subsistência nos seringais pelos seringueiros, tornando-os menos dependentes das cidades, afetando a vida comercial destas (SANTOS, 2001).

Apesar da decadência do extrativismo da borracha ter afetado a rede urbana da Amazônia, no período que se estende de 1920 a 1960, alguns pequenos núcleos urbanos apresentaram um crescimento relativamente importante, como a cidade de Marabá (PA), devido ao fato de, durante a década de 1920, ter se tornado uma importante área de produção de castanha-do-pará e não ter somente embasado sua economia na extração da 
borracha. Outros casos são as cidades do médio vale do Amazonas que, a partir de 1935, tiveram a cultura da produção de juta inserida pelos japoneses.

Razões de ordem política e estratégica fizeram com que a parte periférica do Amazonas, no inicio da década de 1940, fosse desmembrada dos Estados do Pará e Amazonas, originando os Territórios do Amapá, do Rio Branco (atual Roraima) e Guaporé (atual Estado de Rondônia).

A criação dessas unidades administrativas implicou uma revitalização da rede urbana da Amazônia na qual passam a aparecer novas funções urbanas principalmente aquelas vinculadas às atividades governamentais.

As cidades de Belém e Manaus, durante os anos de 1920 e 1960, foram as mais afetadas pela estagnação econômica.

\footnotetext{
"A rede urbana da Amazônia caracteriza-se em 1960, em um dos marcos do período em questão, pela macrocefalia de Belém, então com 377.777 habitantes seguida pela capital amazonense com 152.432. Ambas concentrando $54,52 \%$ da população urbana regional, $52,71 \%$ do pessoal ocupado na indústria e 37,95\% no comércio" (CORRÊA, 1987a, p.56).
}

Ainda durante esse período, novas formas espaciais são introduzidas na Amazônia, anunciando novos padrões que fariam parte da rede urbana regional no período seguinte; a "company town", núcleo implantado por uma grande empresa industrial e o núcleo rural-urbano do "centro", núcleos pequenos, originalmente de natureza rural, localizado longe dos rios, estabelecendo padrão de "centro" em plena mata. Nos anos após o primeiro ciclo da borracha, a economia amazônica permaneceu adormecida frente à economia mundial. Na segunda metade do séc.XIX, a região amazônica insere-se novamente na economia internacional, com a revalorização da borracha.

Essa nova onda de transformações advindas do segundo ciclo da borracha trouxe preocupações oficiais com a demarcação das fronteiras externas, além da ênfase dada às novas expedições científicas para ampliar os conhecimentos científicos da região. A segunda etapa da economia gomífera produziu um intenso povoamento regional, responsável pela incipiente rede urbana.

No Brasil, verifica-se a industrialização maciça de certas áreas no Sudeste, entre 1955-1960, com o intuito de manter a hegemonia da região, assim como a incorporação 
mais efetiva das Regiões Centro-Oeste e Norte, que passaram a se constituir em "fronteiras do capital".

Foi em função desta "fronteira", a partir de 1960, que se verifica um conjunto de transformações na rede urbana brasileira, principalmente na rede urbana amazônica, onde um novo período se inicia.

\begin{abstract}
"A fronteira amazônica só pode, portanto, ser compreendida a partir da inserção do Brasil no sistema capitalista global pós-Segunda Guerra Mundial, em que o capitalismo atua no espaço planetário mas os Estados nacionais conservam suas funções de controle e hierarquização, constituindo a agentes primordiais na produção do novo espaço. $\mathrm{Na}$ verdade, o povoamento da Amazônia a partir da colonização se fez sempre em surtos devassadores vinculados à expansão capitalista mundial" (BECKER, 1998. p. 11).
\end{abstract}

A incorporação, que se inicia a partir da década de 1960, segundo Cardoso e Muller (1977), não compreendia mais uma integração de natureza cíclica à divisão internacional do trabalho sem a criação de uma divisão interna do trabalho, trata-se de uma integração efetiva que teve como suporte o capital constantemente ali aplicado e pelo fluxo de força de trabalho que para lá se deslocou.

Podemos associar o sistema de "expansão" e "ocupação" da Amazônia como uma forma de tentar solucionar mais uma crise do sistema capitalista, que ocorria tanto em nível interno como externo.

"O sistema capitalista é, portanto, muito dinâmico e inevitavelmente expansível, esse sistema cria uma força permanentemente revolucionária, que incessantemente e constantemente, reforma o mundo em que vivemos" (HARVEY, 2005, p.43).

Segundo Harvey (2005), as crises impõem algum tipo de racionalidade e ordem no desenvolvimento econômico capitalista, isso não quer dizer que as crises sejam ordenadas ou lógicas; elas criam condições que forçam algum tipo de racionalização arbitrária no sistema de produção capitalista, porém, essa racionalização apresenta custos sociais e trágicos com conseqüências humanas e ambientais. No caso da região amazônica, por esta se constituir a última fronteira agrícola, pela grande quantidade de recursos minerais, devido ao seu potencial hídrico, tornou-se como uma das alternativas para a crise capitalista que se apresentava no Brasil (NASCIMENTO, 2009).

\title{
Mecanismos utilizados para garantir a ocupação da Amazônia
}


As políticas de colonização da Amazônia se diferenciam por dois fatores: por se constituir como uma colonização dirigida e por suas políticas governamentais, o banco de Crédito da Borracha é transformado em Banco da Amazônia (BASA), e a SPVE é transformada em Superintendência de Desenvolvimento da Amazônia, além da criação da Zona Franca de Manaus, em uma ação planejada do governo para responder a interesses políticos, militares e econômicos. A colonização da Amazônia foi, sobretudo, de natureza política e não se referendou em uma base científica (BECKER, 2001, p.137).

Fatores como a defesa da extensa fronteira nacional, a proteção de riquezas minerais, a conquista de mercados de difícil acesso e o redirecionamento de trabalhadores rurais sem terra de regiões densamente povoadas para as terras amazônicas estavam inseridos dentro do pacote de ações do governo. O discurso oficial de integração nacional, ocupação de vazios demográficos e desenvolvimento faziam parte do plano ideológico de incorporação capitalista da Amazônia. A integração atendia a vários propósitos simultaneamente, e incluía a burguesia nacional, o capital estrangeiro e o Estado Brasileiro (IANNI, 1979; BECKER, 1998; KOHLHEPP, 2002).

Inicia-se então a sétima fase, segundo Corrêa (1987), do processo de periodização da rede urbana amazônica, caracterizada como o período atual, que se inicia em 1960 e perdura até a década de 1990, responsável pelo intenso processo de mudança econômica e urbana na Amazônia.

O Estado apresentou um papel muito importante dentro das políticas de incorporação da Amazônia, foi o responsável pelos investimentos em infraestrutura, o avalista e o repassador dos recursos vindos do exterior, além de estabelecer o conjunto de políticas que concretizariam o propósito de incorporação capitalista da Amazônia.

Segundo Corrêa (1987, p.57); essas políticas se dividiram em três etapas:

1. A primeira etapa se constituía em um controle do excedente demográfico rural, seja do Nordeste, seja do Centro-Sul do país, com intuito de mandar para a Amazônia o excedente rural destas regiões, diminuindo, assim, o afluxo para as áreas metropolitanas, criando, ao mesmo tempo, na Amazônia, um mercado de força de trabalho para o capital. A criação do PIN (Plano de Integração Nacional), em 1970, e do INCRA (Instituto Nacional de Colonização e Reforma Agrária) de onde se originaram os projetos de colonização dirigida, tanto ao 
longo da rodovia Transamazônica, quanto da BR-364, que atravessa o Estado de $\mathrm{RO}$, são resultantes da política implementada nessa primeira etapa.

2. O segundo passo constituía em incorporar a Amazônia ao mercado de consumo de produtos industrializados e de matérias-primas. Para que isso acontecesse, era necessário criar uma rede de infra-estrutura de estradas e rodovias, sendo assim criou-se, em 1960, a ligação rodoviária entre Belém e o sudeste do país através de Brasília e, mais tarde, as rodovias para Porto Velho (BR 364) e Santarém e Cuiabá (BR 163), com isso a produção do Sudeste tinha condições de chegar a Amazônia, assim como agora havia a possibilidade de se enviarem matériasprimas para o Sudeste. Com o intuito de se conhecer melhor os recursos naturais da Amazônia, que possibilitaria a implantação de grandes projetos que iriam propiciar a melhor exploração destes recursos foi criado, em 1968, o Comitê Coordenador de Recursos Energéticos da Amazônia, a Companhia de Pesquisas e Recursos Minerais (CPRM) em 1969, e o Projeto Radar da Amazônia (RADAM) em 1970. A criação da Superintendência da Zona Franca de Manaus (SUFRAMA), em 1967, veio viabilizar a implantação de um distrito industrial, o que causou grandes mudanças na rede urbana.

3. A terceira etapa constituía-se pelo controle capitalista dos recursos naturais sob a forma de apropriação de enormes extensões de terras ricas em madeiras, minérios e solos para a agropecuária. Com o intuito de viabilizar este propósito, foi criado, em 1966, a Superintendência do Desenvolvimento da Amazônia (SUDAM) e organizou-se o seu agente financeiro, o Banco da Amazônia S/A (BASA), órgão responsável pela ocupação privada da Amazônia.

Todos esses fatores, o controle do excedente rural, a criação de força de trabalho disponível para o capital, a inserção da Amazônia no mercado capitalista de produtos e o controle dos recursos naturais são as bases em que se ergueu a "fronteira do capital" na Amazônia (BECKER, 2007).

Essas políticas começaram a ser implantadas com maior intensidade durante o regime militar e estavam regadas pelas idéias da Escola Superior de Guerra (ESG), na qual existia a crença de uma política de integração da segurança nacional sob a tutela de um Governo Federal forte. 
“A política de Colonização Dirigida foi concebida sob o marco que a elite militar responsável pelo Golpe de 1964 estabeleceu. Como antigos estudantes da escola Superior de Guerra (ESG), eles acreditavam numa política de integração da segurança nacional e do desenvolvimento sob a tutela de um Governo Federal forte. Esta crença levada à prática resultou na participação do Governo mais hipertrófica já registrada na história brasileira" (HENRIQUES, 1984, p.396).

A nova região de planejamento, determinada pela SUDAM (Superintendência do Desenvolvimento da Amazônia), a Amazônia Legal, com cerca de cinco milhões de quilômetros quadrados, passou a ser organizada como tirocínio militar, através da “Operação Amazônia”, que mobilizou fundos públicos e privados. A intenção era mostrar a habilidade do novo sistema político em levar adiante o desenvolvimento como potência líder do novo mundo por meio de novas estratégias para explorar seu potencial econômico (KOHLHEPP, 2002, p. 37).

Este período foi marcado por um modelo desenvolvimentista e de integração, pautado por políticas de ocupação de cunho geopolítico, que foi concretizado por meio da implantação de grandes projetos de colonização e de mineração. A política de incentivos fiscais, voltadas, principalmente, para os grandes projetos agropecuários também se fizeram presentes, viabilizando a transformação de áreas florestais em pastagens (MAHAR, 1978; BECKER, 1998; FEARNSIDE, 2005).

A seca na região nordeste, no ano de 1969/70, acelerou a intervenção do governo federal para viabilizar as políticas de colonização para a região Amazônica. A população rural constituía-se como um problema pela sua volatilidade, eram migrantes em potencial e os centros urbanos já apresentavam sinais de inchaço e demandas por saúde, habitação e serviços públicos.

“Logo após a visita do Presidente Médici às áreas afetadas pela seca em março de 1970, foi anunciada a construção da Transamazônica, a pavimentação da Belém-Brasília e a construção de outras estradas ligando a Amazônia e o centro-oeste" (HENRIQUES, 1984a, p.398).

Levando em consideração todos os fatores apresentados, fica difícil acreditar que a política implantada pelo governo militar tinha como interesse principal responder ao desemprego gerado pela crise nordestina de 1970, mas pelas características apresentadas demonstra-se com muito mais clareza as políticas do Estado autoritário, que tinha como interesse fazer frente aos interesses internacionais na Amazônia. Essas políticas representaram, por outro lado, uma forma de aliviar as tensões sociais no campo sem 
que necessariamente se realizasse uma reforma agrária (IANNI, 1979; KOHLHEPP, 2002).

A partir da década de 70, através de investimentos públicos inicia-se a extensão da fronteira Amazônica, com a Transamazônica e implantação da política de colonização sustentada pelo PIN ${ }^{2}$ (Programa de Integração Nacional).

Segundo Henriques (1984, p.399), os objetivos específicos do PIN eram:

a) Deslocar as fronteiras econômicas, particularmente as agrícolas para os bancos da Amazônia;

b) Criar as condições que possibilitassem a incorporação da região na economia de mercado, fornecendo a um enorme segmento da população, até então dispersa e estagnada, as condições necessárias para a produção e o conseqüente poder de compra;

c) Estabelecer as bases para a efetiva transformação agrícola da região semi-árida do Nordeste;

d) Redirecionar o potencial migratório do Nordeste para os vales úmidos desta região e para suas novas fronteiras agrícolas, evitando assim seu deslocamento para as áreas urbanas do Centro Sul; e,

e) Assegurar ao Nordeste o apoio do Governo Federal, a fim de garantir um processo de industrialização que permitisse a consecução e autosustentação das metas de desenvolvimento programadas.

Estas metas não foram as únicas políticas implantadas pelo Estado. Uma série de decretos foi criada viabilizando legalmente o propósito do Estado.

\footnotetext{
"Foi definida uma área prioritária ao longo da Transamazônica para realizar a reforma agrária; criado o Departamento Regional do INCRA; determinado que os projetos de reforma agrária deveriam incluir 100 mil unidades familiares; convocadas a organização de 100 cooperativas, a realização de estudos sobre as condições socioeconômicas da área e de um arquivo técnico de referências sobre a região; exigida a legalização dos títulos de posse das terras em favor dos posseiros que no momento ocupavam a terra e, finalmente, determinado que os recursos para o empreendimento todo seriam previstos pelo INCRA e pelo PIN".

"A aplicação destas políticas na área liberou 6,5 milhões de hectares na região prioritária e 2,2 milhões de $\mathrm{Km}^{2}$ situados numa faixa de extensão de 100 quilômetros em ambos os lados das rodovias na região da Amazônia,
}

\footnotetext{
${ }^{2}$ A política de desenvolvimento incorporada pelo PIN tinha como objetivo fundamental a redução dos desequilíbrios regionais e a descentralização do processo de desenvolvimento através da criação de novos centros de progresso.
} 
deixando a cargo do governo a distribuição das terras" (HENRIQUES, 1984b, p.399).

Os serviços básicos aos colonos recém-chegados seriam fornecidos pelas agências federais. O Instituto Nacional de Colonização e Reforma Agrária (INCRA) teria a função de demarcar e prover os lotes aos colonos, construir agrovilas e providenciar os serviços de saúde e educação até que fossem assumidos por agências específicas.

Dentre as agências envolvidas no processo a Associação de Crédito e Assistência Rural (ACAR) daria assistência técnica, o Banco do Brasil forneceria crédito a juros baixos enquanto a Companhia Brasileira de Alimentos (COBAL) faria a distribuição de alimentos a preços mais acessíveis. O serviço de saúde seria executado pela Fundação Serviço Especial da Saúde Pública (SESP) e pela Superintendência de Campanhas de Saúde Pública, que atuariam no combate à malária.

Os recursos necessários para a aplicação de todas essas políticas viriam da transferência de 30\% dos incentivos fiscais ao Plano de Integração Nacional (PIN). Segundo Henriques (1984), as metas do INCRA de estabelecer 100 mil famílias de 1971-1974 nunca foi atingida, em 1974 somente 5.717 famílias tinham se estabelecido nos projetos de Marabá, Altamira e Itaituba, grande parte desse fracasso associa-se aos problemas associados à terra, principalmente a baixa fertilidade.

Apesar de todo o esforço para a implantação do Plano de Integração da Amazônia, os frutos esperados não ocorreram; não havia estudos acerca do solo Amazônico no momento em que as políticas de colonização foram implantadas, acreditava-se que a exuberante vegetação, em um clima tropical, apresentasse um solo rico.

Foram os estudos do RADAMBRASIL ${ }^{3}$, na década de 1970, que demonstraram a baixa fertilidade natural dos solos amazônicos, fator este que contribuiu para que os programas de colonização não obtivessem o êxito esperado. Fatores como a origem dos migrantes, que se constituíam, na sua grande maioria, de camponeses nordestinos ${ }^{4}$,

\footnotetext{
${ }^{3}$ O RADAMBRASIL foi um projeto desenvolvido na década de 70 pelo Ministério de Minas e Energia com o intuito de fazer o mapeamento básico da qualidade do solo, vegetação, geologia, aptidão agrícola e uso potencial da terra de todas as regiões brasileiras. A pesquisa foi realizada com o auxilio dos recursos de radar.

${ }^{4}$ Em 1971, uma pesquisa ministrada pelo Instituto de Planejamento Econômico e Social (IPEA) concluiu que, em dez projetos de colonização executados pelo governo nas Regiões Norte e Centro-Oeste, o local de origem dos migrantes foi fator definidor de muitas das suas características. $\mathrm{O}$ outro fator que veio à tona quando se analisou os resultados da política de colonização é que, dentre os nordestinos que vieram para a Amazônia, predominou aqueles com perfis menos privilegiados: a média da escolaridade era inferior a um ano; tinham sido na sua maioria trabalhadores familiares ou meeiros (62\%), conseqüentemente suas condições socioeconômicas eram as piores; mesmo assim, eles tiveram as
} 
analfabetos, em precárias condições de saúde, inadequados hábitos nutricionais, associados à falta de uma adequada infra-estrutura de saúde fez com que o índice de desistências aumentasse, em decorrência da impossibilidade de se adaptar ao novo ambiente (HENRIQUES, 1984). Os que permaneciam, deparavam-se com um novo problema, a falta de suporte estrutural, inadequados sistemas de crédito, precariedade do sistema viário, inexistência de meios de transportes para o escoamento, o que dificultava o aproveitamento da terra (IANNI, 1979; HENRIQUES, 1984).

A inadaptabilidade dos colonos associada à degradação que esse tipo de colonização vinha causando, visto que as massas de colonos espontâneos tinham suas atividades voltadas para a destruição da mata e o esgotamento do solo, levou a um novo tipo de colonização que permaneceu sob o domínio das grandes empresas.

\footnotetext{
“A construção da Transamazônica propiciaria, ao mesmo tempo, a expansão capitalista na Amazônia e o deslocamento de trabalhadores rurais do Nordeste, tudo isso em nome da integração nacional, da segurança interna, ou da doutrina de segurança e desenvolvimento. Mas cabe não esquecer o próprio empreendimento da construção da rodovia, que pode ter representado uma oportunidade a mais, de negócios de grande vulto, para as empresas privadas de terraplanagem, engenharia de estradas e pontes, agrimensura etc" (IANNI, 1979, p. 53).
}

Como suporte para a concretização da mudança de visão das autoridades superiores, foi implantado o II Plano de Desenvolvimento para a Amazônia compreendido entre os anos de $1975-1979$.

O PND II (Programa Nacional de Desenvolvimento II), de 1974, tinha como meta defender nas terras fronteiriças, uma política capitalista em detrimento da agricultura familiar, uma política de ocupação do tipo extensiva e abrangente passou a ser implantada na região, concentrando os investimentos em grandes empreendimentos estatais e privados, que tinham maior probabilidade de retorno em curto prazo, privilegiando as áreas que já apresentavam alguma concentração econômica e populacional (COSTA, 1997).

Esta mudança de política manifestada no II Plano de Desenvolvimento da Amazônia, enfatizava a ocupação de lotes entre 500 e três mil hectares, com o intuito de

porcentagens mais baixas de resposta quanto aos motivos ditos. A história migratória deles era a mais simples dentre todos os grupos: eles deixaram seus projetos de origem com as idades mais adiantadas, chegaram aos locais dos projetos nos seus inícios e fizeram em média apenas um movimento. Apesar de mostrar locais de destinos diversificados, mais rurais que urbanos, eles chegaram aos locais dos projetos onde foram entrevistados com pouquíssimo capital (Tavares apud Henriques, 1984). 
atrair as grandes empresas de capital agrícola e criação de gado, fossem elas nacionais ou estrangeiras, para a região amazônica. As consequências desta mudança foram a elevação dos preços das terras expropriadas, a concentração de lotes de 100 hectares, assim como sua venda e a invasão de terras privadas e reservas indígenas. Estes processos transformaram a terra de bem de produção para objeto de especulação.

No ápice do desenvolvimento econômico pelo qual passava o Brasil, segundo Castro (2010), foi a mentalidade do eldorado, que, segundo a autora, é o fundamento do processo de ocupação da região, onde, no nível do imaginário, constroem-se a relação do homem com a natureza, e necessariamente, com os modelos utilizados para sua transformação em mercadoria, que se desenvolvem as estratégias de planejamento regional da Amazônia, centradas em pólos de crescimento, os pólos de desenvolvimento ou Programa POLOAMAZÔNIA, previstos no Segundo Plano de Desenvolvimento Nacional (1975-79).

Os pólos de desenvolvimento foram baseados em pontos focais setoriais separados como, por exemplo, a extração de recursos minerais ou áreas de criação de gado com possível processo industrial (KOHLHEPP, 2002, p.39).

A política dos pólos de desenvolvimento foi vantajosa para os investidores de capital nacional e internacional, atraídos pela redução de taxas tributárias. O pacote de benefícios se estendeu também para os bancos, companhias de seguro, mineradoras e empresas estatais de transporte e construção de estradas, que investindo na devastação da floresta tropical, poderia introduzir projetos de criação de gado, com subsídios fiscais, realizando a exploração de terras a preços baixos (KOHLHEPP, 2002).

Segundo Kohlhepp (1997), no programa POLOAMAZÔNIA, o conceito de pólos de crescimento foi mal interpretado e o resultado não foi a descentralização do desenvolvimento, mas um aumento das disparidades do desenvolvimento inter e intra regional, aonde a periferia se tornou ainda mais dependente do centro, em nível nacional e internacional, fazendo surgir enclaves mantidos artificialmente.

O fracasso das políticas aplicadas, sobretudo, a das fazendas de gado, impulsionou as idéias de colonização agrícola por pequenos agricultores, através do Programa POLONOROESTE (Programa Integrado de Desenvolvimento do Noroeste do Brasil), implantado em Rondônia e no norte do Mato Grosso, que teve como intuito absorver contingentes populacionais de mão de obra, por meio de melhoria de 
infraestrutura, aumento de produtividade agrícola e da geração de renda das atividades agropecuárias por meio de financiamentos concedidos pelo Banco Mundial (KOHLHEPP, 2002).

Segundo Kohlhepp (2002, p. 40) o POLONOROESTE, estava embasado em três premissas:

1. Deveria incluir classes rurais de nível social mais baixo como grupos alvo;

2. Desenvolvimento de estratégias para a satisfação de necessidades básicas; e

3. Incentivo para métodos participativos.

Um enorme onde de migrantes espontâneos da região sul e sudeste foram atraídos pela distribuição de terras que logo se esgotaram, o que causou um aumento de terras apossadas e assentamentos descontrolados em áreas com capacidade agrícola reduzida, além de inúmeros conflitos com posseiros e grileiros.

Todos estes problemas acarretaram o fracasso do programa POLONOROESTE, que apresentou como sucessor alguns anos mais tarde, o PLANAFLORO (Plano Agropecuário e Florestal de Rondônia), que previa a reorganização da problemática social e ecológica do estado.

\footnotetext{
"O Planafloro continha uma série de componentes que objetivavam mitigar os problemas causados por seu antecessor e incluía uma série de objetivos relacionados à proteção ambiental. Um pré-requisito para a aprovação do empréstimo por parte do Banco Mundial foi a criação do Zoneamento Agroecológico de Rondônia, que foi aprovado pela Assembléia Legislativa em junho de 1988. Além de dividir o estado em seis zonas diferentes, o Zoneamento foi desenvolvido com o objetivo de assegurar uma utilização controlada dos recursos naturais existentes em Rondônia" (PEDLOWSKI $e t$ al. 1999).
}

O Programa Grande Carajás e o Projeto Calha Norte representaram a continuidade dos programas da década de 1980, dentro da nova realidade econômica do Brasil e das novas formas como o governo remodela suas ações sobre a Amazônia (PRATES, 2008).

O Projeto Calha Norte $(\mathrm{PCN})$ vem reafirmar a política militar de ocupação regional, entendida como a única solução para os conflitos crescentes na área. Sob a responsabilidade da Secretaria da Defesa Nacional, o PCN foi implantado em 1985, situado ao norte das calhas do rio Solimões, e do Amazonas ao longo das fronteiras com Colômbia, Venezuela, Guiana, Suriname e Guiana Francesa (BECKER, 1998, p. 80). 
O Projeto Calha Norte consistiu fundamentalmente em bases militares com controle do aparato tecnológico, fundamentado em armas modernas e atuando em seis pólos que tem como base de apoio núcleos urbanos e numerosos aeródromos espalhados na região. Sua função é garantir a presença estratégica e a movimentação tática das forças armadas no controle sócio-econômico-militar da região, apaziguar conflitos e acelerar a produção hidrelétrica (BECKER, 1998, p. 82)

As fases mais recentes de ocupação da Amazônia, inaugurada nos anos oitenta, conjugaram esforços voltados à mineração, agroindústria e a reforma agrária, sendo colocada a mineração como centro do desenvolvimento regional (KITAMURA, 1994).

Nos anos 90 teve início o cultivo de soja na região, prometendo mudanças nos modelos de ocupação da Amazônia e na economia regional, com previsão de abertura de corredores multimodais, integrando hidrovias, ferrovias e rodovias (CARVALHO, 1999).

\section{A Urbanização da Amazônia}

Segundo Harvey apud Becker (1978), o fenômeno urbano na região Amazônica deve ser analisado segundo o conceito de que as cidades são construções geradas pela mobilização, extração e concentração geográfica de quantidades significantes do produto excedente socialmente designado. Os povoados, ou seja, a menor categoria do fenômeno urbano consiste na maneira mais eficiente de estudo da urbanização da Amazônia. Estes povoados tiveram seu desenvolvimento, a partir da construção das rodovias, com maior ênfase quando da construção da rodovia Belém-Brasília.

\footnotetext{
"Povoados são núcleos populacionais especialmente compactos com nomes reconhecidos localmente, que possuem caráter rural-urbano. São residências de trabalhadores rurais ou de pequenos agricultores em pequenos centros de mercado. Não possuem, assim, a variedade de funções, a complexidade social, e o status legal, critérios necessários à sua classificação como centros urbanos segundo a teoria contemporânea. Contudo, de acordo com o conceito adotado, é possível considerar os povos como uma manifestação de urbanismo, sua forma particular, estando vinculada à sua função no padrão global de circulação do produto excedente socialmente designado. Essas incipientes formas de urbanismo constituem a base local de operação, elo de uma grande cadeia que mobiliza o excedente em favor da classe mais poderosa e suas expressões espaciais - as metrópoles (nacionais e internacionais" (BECKER, 1978, p.111).
} 
Segundo Becker (1978), foi a organização agrária efetivada sob o desenvolvimento capitalista pós-1930, o fator responsável pela emergência dos povoados. A introdução de um novo modo de produção baseada na substituição das exportações, que substituía a economia agroexportadora, possibilitou condições institucionais para a predominância da estrutura produtiva de base urbano-industrial, assim como a expansão das atividades vinculadas ao mercado externo.

Esses povoados não possuem a complexidade e os critérios para se enquadrarem nas teorias urbanas contemporâneas, mas estão vinculados ao padrão global do produto excedente. Essas incipientes manifestações de urbanização são responsáveis por mobilizar o excedente a favor dos grandes centros do sul e sudeste do país (IANNI, 1979; BECKER, 1998).

Os núcleos urbanos da Amazônia, além do seu papel clássico de circular mercadoria, capital e informação, têm a função de organizar o mercado de trabalho, com pontos de concentração e redistribuição da força de trabalho.

O período de substituição das importações compreendido entre 1930 e 1960, durante o período da industrialização, tinha como esforço favorecer a empresa industrial, a função do sistema agrícola era permitir a estabilidade do sistema, fornecendo mão-de-obra barata e alimentos para os trabalhadores urbanos, fatores que permitiram a empresa industrial se capitalizar.

A expansão contínua horizontal do território foi outro fator responsável pela acumulação da empresa industrial, que ocorreu sob a forma de acumulação primitiva estrutural, em que se expropria do excedente criado pela posse transitória da terra por trabalhadores rurais (BECKER, 1978).

\footnotetext{
"Este mecanismo foi responsável pela acumulação urbana, pela emergência de um proletariado rural e pela expansão da fronteira agrícola que, apoiada na construção de rodovias, produzia alimento barato para o mercado interno. Iniciando em torno de São Paulo, a fronteira avançou gradativamente para os estados centrais, alcançando a borda da Amazônia" (BECKER, 1978a, p.112).
}

Novos elementos condicionantes à urbanização e à expansão da fronteira agrícola ocorreram pós 1960 na região amazônica, foi a possibilidade da grande empresa reproduzir o excedente através da sua expansão, não somente por políticas de incentivos fiscais ou financiamentos especiais, mas sobre as mais variadas formas. 


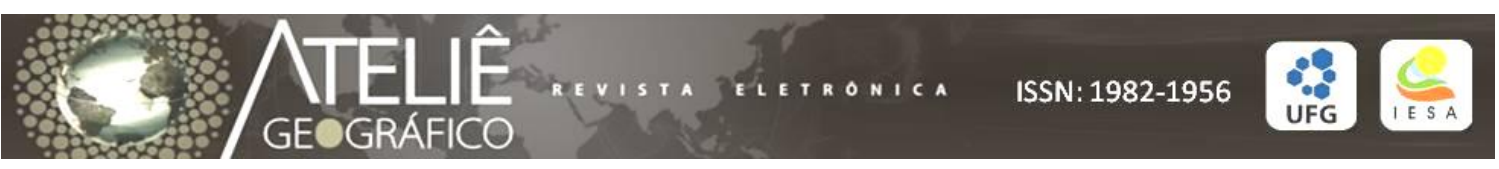

Segundo Becker (1998), as formas mais importantes de reprodução do excedente parecem ser: a) o próprio incentivo fiscal e financiamentos; b) a apropriação de terras, uma vez que estão sofrendo uma fantástica elevação de preço; c) a possibilidade de exportar para a região, e da região.

O processo de ocupação da Amazônia se intensificou, segundo Becker (1998), com a formação do moderno aparelho de estado brasileiro, associado à sua crescente intervenção na economia e no território, com base na predominância da ideologia da segurança nacional. Além disso, a necessidade de unificar o mercado nacional, associado ao avanço da industrialização, também contribuiu para explicar a necessidade de desbravar a região.

Para que a Amazônia fosse o local de expansão da fronteira agrícola, para a manutenção do processo de industrialização, era necessário ligar a Amazônia ao centro do país. Sendo assim, rodovias foram construídas ou pavimentadas e a migração foi estimulada (IANNI, 1979; BECKER, 1998; KOHLHEPP, 2002). O revigoramento das rodovias traz a troca da velha estrutura de circulação fluvial, que caracterizava a chamada ocupação beiradeira, pela trama viária terrestre, ligando os novos núcleos urbanos, que surgiam ao longo das rodovias, trazidos pela colonização oficial ou espontânea (BECKER, 2004).

\footnotetext{
“O povoamento regional da Amazônia, nas últimas três décadas alterou estruturalmente o antigo padrão secular, fundamentado na circulação fluvial. As rodovias atraíram a população para a terra firme e para as novas áreas, abrindo clareiras na floresta, e sob o influxo da nova circulação a Amazônia se urbanizou e se industrializou, embora com sérios problemas sociais e ambientais" (BECKER, 2004, p.73).
}

A mudança na escala da mobilização excedente associada às políticas adotadas pelo governo militar intensificou o processo de urbanismo na região amazônica, englobando desde a metropolização até a emergência de povoados ao longo de novas rodovias ou de rodovias revitalizadas por onde circula o excedente.

Face às mudanças provenientes da chamada, segundo Corrêa (1987), "fronteira do capital", que incluía mudanças na esfera produtiva e nas relações de produção, a ocupação espontânea ou dirigida da região, a abertura de rodovias e a implantação de grandes projetos agropecuários, de mineração e hidrelétricos acarretaram transformações na rede urbana. 
As formas espaciais e as funções urbanas do passado, ou seja, os fixos conforme Milton Santos, não se perderam, mas continuam presentes, porque se fazem necessárias nas áreas da Amazônia ainda pouco afetadas pelas transformações da "fronteira do capital". Nas últimas décadas, a urbanização da população amazônica tem sido ampliada. Segundo o IBGE (Instituto Brasileiro de Geografia e Estatística) em 1940, a população urbana representava 27,7 \% do total, já em 1960 crescia para 37,7\%, chegando em 1980 a 51,6\% do contingente demográfico da região.

Outro aspecto que deve ser levantado sobre a urbanização da Amazônia é a elevada concentração que vem ocorrendo nas últimas décadas em poucos centros urbanos. Segundo o IBGE em 1960, a população das seis capitais políticoadministrativas: Belém, Manaus, Porto-Velho, Macapá, Rio Branco e Boa Vista representavam $62,1 \%$ da população urbana da região, dentre elas Manaus e Belém sozinhas eram responsáveis por 54,5\% do efetivo urbano da Amazônia. Já em 1980, 64,3\% correspondiam à população urbana das seis capitais político-administrativas (Belém, Manaus, Porto-Velho, Macapá, Rio Branco e Boa Vista) sendo 53,8\% correspondente somente à população urbana de Manaus e Belém.

A transformação ocorreu durante os anos de 1960 a 1980 na Amazônia tem privilegiado as cidades capitais, onde $65,4 \%$ do aumento da população urbana foram devido às seis cidade mencionadas. Núcleos de povoamento, que se apresentavam estagnados ou que nunca tinham apresentado maior importância, com a abertura de rodovias de penetração associado à valorização econômica se revitalizaram.

\section{A ocupação efetiva da Amazônia e os projetos de colonização}

A construção da BR-364 em Rondônia e a colonização ali implantada pelo INCRA a partir da década de 1970, foram fatores responsáveis pelo revigoramento de antigos e inexpressivos lugarejos, que se constituíam em modestos centros vinculados a um decadente extrativismo da borracha, garimpagem de diamantes e cassiterita, além daqueles lugares implantados no começo do século em razão das linhas telegráficas de Marechal Rondon.

Dentro desse contexto podemos destacar a colônia Paulo Assis Ribeiro (Vilhena), Ji-Paraná (Pimenta Bueno), Ouro Preto (Ji-Paraná) e Marechal Dutra e Burareiro 
(Ariquemes). Podemos destacar também o crescimento de Porto Velho, que se beneficiou da política rodoviária implantada com a construção da BR-364 e alcançou um crescimento demográfico e econômico de seus arredores, que permitiu a ampliação de suas funções administrativas, políticas e de serviços. Segundo o IBGE (Instituto Brasileiro de Geografia e Estatística) sua população passou de 3.148 habitantes em 1940 para 19.293 em 1960 e 101.162 , em 1980.

As políticas de colonização, os projetos agropecuários, o desenvolvimento das atividades de mineração de pequeno e grande porte, viabilizados pela abertura da rodovia transamazônica, geraram o rejuvenescimento de pequenos núcleos urbanos ribeirinhos no afluente do Amazonas, que se encontravam estagnados desde a crise da borracha.

Os exemplos mais expressivos são Maranhão (rio Tocantins), Altamira (rio Xingu), Itaituba (rio Tapajós) e Humaitá (rio Madeira), esses locais passaram a desempenhar papel de centros de mão-de-obra para os garimpeiros e para as grandes fazendas dos arredores.

\begin{abstract}
"O crescimento destes centros, no período 1960-1980, foi notável: Marabá passa de 8.342 habitantes para 41.647, enquanto Altamira evolui de 2.883 para 24.812. Em ambos os casos o incremento demográfico mais significativo deu-se no período 1970-1980. O modesto núcleo de Itaituba, por sua vez, alcança a 19.584 habitantes em 1980, enquanto a decadente Humaitá, que entre 1960 e 1970 apresentara decréscimo de população, passando de 1.184 para 1.165 habitantes, alcança em 19809.862 habitantes e o caso também de Santarém, tradicional capital regional do médio vale amazônico, na confluência do tapajós com o Amazonas. Cidade que se beneficiaria da introdução da cultura da juta e da valorização da pecuária em sua região de influência, não conheceu a estagnação que conheceram as cidades que dependiam exclusivamente da borracha. Assim, sua população passa de 7.527 habitantes em 1940 para 24.498, em 1960. Transformada em ponto final da Rodovia Cuiabá-Santarém, beneficiou-se do crescimento demográfico e econômico de sua hinterlândia, introduzindo-lhe novo dinamismo: sua população ascende para 51.004 habitantes, em 1970 e 102.181, em 1980" (CORRÊA, 1987b, p.61).
\end{abstract}

O processo de rejuvenescimento dos antigos núcleos ribeirinhos implicou em mudanças tanto na organização espacial quanto na organização social que se diversifica na forma de comerciantes novos, pessoas ligadas ao transporte fluvial e rodoviário, funcionários públicos, pessoas no setor comercial e de serviços tanto formais quanto informais, migrantes, peões entre outros. 
O dinamismo responsável pelo rápido crescimento desses centros urbanos não ocorreu com a mesma intensidade nas cidades ribeirinhas do Amazonas ou dos baixos cursos de seus afluentes. Estes centros foram afetados pela circulação rodoviária e por uma menor valorização dos seus arredores, gerando uma estagnação de suas áreas de influência.

\begin{abstract}
“Assim a cidade de Cametá, com 5.654 habitantes em 1960, atinge a 15.516 em 1980; Óbito passa de 5.290 para 17.117, enquanto Monte Alegre de 3.842 para 10.682 . Em 1960, as três supramencionadas cidades eram maiores que Altamira, tendo sido, no entanto, superadas por esta, em 1980. Mesmo as mais importantes como Parintins e Itacoatiara não apresentam o dinamismo das cidades Transamazônicas: a população delas evolui de cerca de 8.800 habitantes para cada uma, em 1960, para cerca de 28 mil, em 1980" (CORRÊA, 1987c, p.62).
\end{abstract}

O aparecimento de atividades modernas em larga escala, como a mineração, trazem mudanças na rede urbana que se traduzem na criação de um novo tipo de cidade a "company town", bem como a introdução de um novo tipo de relação com o espaço exterior ao do núcleo.

\begin{abstract}
"A company town implantada na Amazônia, como em outras regiões, é uma criação planejada, dotada de moderna infra-estrutura e dos serviços essenciais, e onde tudo está sob o controle, direto e indireto, da empresa que a criou e a administra. A criação da cidade e sua manutenção fazem parte, na realidade, dos investimentos necessários para tornar viável a exploração, em larga escala, dos recursos naturais em área não habitada e sem nenhuma infra-estrutura. Cria-se então um "enclave" urbano dotado de abastecimento de água, rede de esgoto, energia elétrica, coleta de lixo, policiamento próprio, transporte coletivo, instalações de telecomunicações e moderno aeroporto" (CORRÊA, 1987d, p.62).
\end{abstract}

A população ali residente possuía uma organização espacial mais completa com hospital, escolas, clubes recreativos e esportivos, cinema supermercado e lojas localizadas em um pequeno centro comercial. A company town representa a implantação do moderno na Amazônia, introduzindo uma paisagem e um estilo de vida aleatório aos da população regional. Mas as cidades segundo esse padrão reproduzem o padrão clássico da cidade brasileira: bairro dos quadros técnicoadministrativos superiores, bairro de nível intermediário e bairros operários, cada um deles distinguindo-se nitidamente na paisagem urbana (KOHLHEPP, 2002; BECKER, 1998). 
No que diz respeito às relações espaciais, a company town apresenta autonomia em face da rede urbana amazônica, sua produção sai diretamente pelos portos, terminais ferroviários ou diretamente dos depósitos para o exterior, para outros portos ou para núcleos urbano-industriais do sudeste do país. Estes núcleos urbanos “company town” estão associados às grandes empresas de exploração mineral tais como a CVRD (Companhia Vale do Rio Doce).

As atividades mineradoras, que assumem a forma de garimpagem, também geram núcleos de povoamento que assumem características urbanas, alguns apresentam caráter de instabilidade enquanto outros apresentam um aparente caráter de permanência.

A partir dos anos 1970 e, sobretudo, após 1980, os núcleos de povoamento ligados a extração de ouro de aluvião ou de terra-firme ampliaram-se em número e em tamanho (SANTOS, 2001). Esses núcleos localizavam-se nos vales do rio Madeira, Tapajós, Xingu, Tocantins, Negro e de seus afluentes e nas áreas de extração em depósitos não aluvionários como em Serra Pelada, no sul do território Paraense. Novos e espontâneos núcleos de povoamento passaram a surgir ao longo das rodovias, nas proximidades de áreas em desbravamento, formadas geralmente de pequenos lavradores, médios e grandes fazendeiros.

Os núcleos espontâneos constituíam-se, inicialmente, nas áreas rurais, comportando pequenos lavradores e posseiros em grande parte. Com a expansão das fazendas de gado, ocorre a expropriação dos posseiros e a ampliação da mão de obra assalariada, os povoados transformam-se em habitat rural, concentrando trabalhadores rurais assalariados temporários.

O processo de colonização dirigida, ao longo da rodovia transamazônica, calcouse durante o começo da década de 1970, sob uma política de concentração da população rural em pequenos núcleos de povoamento e na criação de uma rede hierarquizada de pequenos serviços. Passa-se a dotar uma diferenciação hierárquica de núcleos de povoamento: agrovila, agrópolis e rurópolis, essa política durou pouco tempo, pois se passou a privilegiar os grandes projetos agropecuários (IANNI, 1979).

\section{Conclusão}


A Amazônia é considerada hoje, uma floresta urbanizada (BECKER, 2001), apresentando uma população estimada em vinte milhões, dos quais $60 \%$ são urbanos, ou seja, 12 milhões de habitantes residem em cidades, segundo dados do censo de 2000. Grande parte dessa população encontra-se distribuída nas cidades grandes (cidades que ultrapassam a faixa dos 500 mil habitantes).

O padrão de ocupação mostra que a concentração do povoamento ocorreu, sobretudo, ao longo dos eixos de circulação fluvial e dos eixos rodoviários, denominado por SÉRRE (2001), de Amazônia dos rios e Amazônia das estradas. Essa forma de ocupação teve suas raízes na história da região.

Dois períodos foram importantes na evolução das cidades da Amazônia, o primeiro foi o período da borracha, no final do século passado e o segundo foi o período de abertura do espaço amazônico e sua interação ao espaço nacional, a partir de políticas de ocupação deste espaço com a construção de centenas de quilômetros de estradas. Foi este segundo momento o responsável pela implantação de uma dinâmica de urbanização fora dos padrões naturais e sociais da região.

Esse modelo de urbanização dirigida, fez com que os núcleos urbanos da Amazônia, assumissem uma lógica econômica fora dos padrões locais, além de assumirem a função de atrativo populacional e de integração social, segundo modelos definidos impulsionados pelo Estado.

Este modelo urbano que se estabelece na Amazônia, além de não ter seguido os padrões e necessidade das populações locais, são reflexo dos processos sociais ligados ao crescimento do país.

As transformações pelas quais a rede urbana amazônica passou, a partir da implantação dos projetos de colonização, fez destas cidades não mais uma rede urbana dendrítica, com a função de escoar os produtos referentes ao extrativismo e a mineração, mas assumindo uma forma mais complexa dentro do quadro urbano amazônico.

Estes elementos contribuíram para que se estabelecesse na Amazônia uma rede de cidades que não representam mais a expressão do capital mercantil nem a condição para o seu funcionamento, mas adquire novos significados, através das modificações funcionais e na organização interna dos núcleos pré-existentes e da criação de novos núcleos pelo capital industrial, financeiro ou pelo estado capitalista. Estes formam os 
agentes responsáveis pela introdução de novas atividades, populações e relações sociais de produção na Amazônia e que permitiram os centros urbanos amazônicos adquirirem a complexidade atual.

\section{Referências Bibliográficas}

BECKER, B. K. Uma hipótese sobre a origem do fenômeno urbano numa fronteira de recursos do Brasil. Revista Brasileira de Geografia, Rio de Janeiro, v.40, n.1, p.111$122,1978$. Amazônia. São Paulo: Ática, 1998.112p.

Revisão das políticas de ocupação da Amazônia: é possível identificar modelos para projetar cenários? Parcerias Estratégicas, Brasília, v.12, n.1, p.135-159, 2001.

2004.168p.

Amazônia: Geopolítica na virada do III milênio. São Paulo: Ática,

A Amazônia e a política ambiental brasileira. In: SANTOS, M.;

BECKER, K. B. (Ed.). Território, territórios: ensaios sobre o ordenamento territorial. Rio de Janeiro: Lamparina, 2007, p. 22 - 40.

BROWDER, J.O.; GODFREY, B.J. Rainforest Cities: Urbanization, development, and globalization of the Brazilian Amazon. New York: Columbia University Press, 1997. $429 \mathrm{p}$.

CASTRO, E. Políticas de Estado e atores sociais na Amazônia contemporânea. In: BOLLE, W.; CASTRO, E.; VEJMELKA, M. (Ed.). Amazônia: Região Universal e Teatro Mundial. São Paulo: Editora Globo, 2010, p. 105-122.

CARDOSO, F. H.; MÜlleR, G. Amazônia: expansão do capitalismo. São Paulo: Brasiliense, 1977. 205p.

CARVAlHO, R. A Amazônia rumo ao 'Ciclo da soja'. Amazonia Papers, São Paulo, v. 01, n. 02, p. 1-8, 1999. Disponível em: (URL: http://www.amazonia.org.br)

CORRÊA, R. L. A Periodização da Rede Urbana da Amazônia. Revista Brasileira de Geografia, Rio de Janeiro, v. 49, n.3, p.39-68, 1987.

COSTA, W.M. O Estado e as Políticas Territoriais no Brasil. 7. ed. São Paulo: Contexto, 1997. 83 p.

FEARNSIDE, P. Desmatamento na Amazônia brasileira: história, índices e conseqüências. Megadiversidade, Belo Horizonte, v.01, n.01, p. 113-123, 2005.

FIEBGE - Fundação Instituto Brasileiro de Geografia e Estatística. A Organização do Espaço na Faixa da Transamazônica. Rio de Janeiro: FIBGE, v. 50, 1979.

GONÇALVES, C. W. P. Amazônia: Amazônias. São Paulo: Contexto, 2001. 178p. 
HARVEY, D. A Produção Capitalista do Espaço. São Paulo: Annablume, 2005. 250 p.

HENRIQUES, M. H. F. T. A política de colonização dirigida no Brasil: um estudo de caso, Rondônia. Revista Brasileira de Geografia, Rio de Janeiro, v. 46, n.3/4, p. 393423, 1984.

IANNI, O. Colonização e Contra-Reforma Agrária na Amazônia. Petrópolis: Vozes, 1979. $140 \mathrm{p}$.

IBGE - Instituto Brasileiro de Geografia e Estatística. Censo Populacional. Rio de Janeiro. 1940, disponível em:

http://biblioteca.ibge.gov.br/visualizacao/monografias/GEBIS\%20-

20RJ/CD1940/Censo\%20Demografico\%201940\%20VII_Brasil.pdf, acessado em $12 \mathrm{de}$ março de 2011.

. Censo Populacional. Rio de Janeiro. 1950, disponível em:

http://biblioteca.ibge.gov.br/visualizacao/monografias/GEBIS\%20-

\%20RJ/CD1950/CD_1950\%20_vIII_T1_Brasil.pdf, acessado em 12 de março de 2011.

Censo Populacional. Rio de Janeiro. 1960 , disponível em:

http://biblioteca.ibge.gov.br/colecao_digital_publicacoes_multiplo.php?link=CD1960\&t itulo=Censo\%20Demogr\%E1 fico\%201960, acessado em 12 de março de 2011.

Censo Populacional. Rio de Janeiro. 1970, disponível em:

http://biblioteca.ibge.gov.br/colecao_digital_publicacoes_multiplo.php?link=CD1970\&t itulo=Censo\%20Demogr\%E1fico\%201970, acessado em 12 de março de 2011.

Censo Populacional. Rio de Janeiro. 1980, disponível em:

http://biblioteca.ibge.gov.br/colecao_digital_publicacoes_multiplo.php?link=CD1980\&t itulo=Censo\%20Demogr\%E1fico\%201980, acessado em 12 de março de 2011.

Censo Populacional. Rio de Janeiro. 2000, disponível em:

http://biblioteca.ibge.gov.br/colecao_digital_publicacoes_multiplo.php?link=CD2000\&t itulo=Censo\%20Demogr\%E1fico\%202000, acessado em 12 de março de 2011

KITAMURA, P.C. A Amazônia e o Desenvolvimento Sustentável. Ed. EMBRAPA SPI 1. ed. 1994. $182 \mathrm{p}$.

KOHLHEPP, G. Regional Policies in Brazil: the Spatial Impact of State Activity in Amazonia. In: T. Van et al. (eds.). The diversity of development: essays in honour of Jan Kleinpenning. Assen: Van Gorcum, 1997. p. 231-240.

- "Conflitos de Interesse no ordenamento territorial da Amazônia brasileira”. Estudos Avançados, São Paulo, v. 16, n. 45, p. 37-61, 2002.

MAHAR, D.J. Desenvolvimento econômico da Amazônia: uma analise das políticas governamentais. Rio de Janeiro: IPEA, 1978. 259p. 
NASCIMENTO, C. P. Cenários da Produção Espacial Urbana de Porto Velho. 2009. 210p. Dissertação (Mestrado em Geografia) - Universidade Federal de Rondônia, UNIR, Porto Velho, 2009.

PEDLOWSKI, M.; DALE, V.; MATRICARDI, E. The creation of protected areas and the limits of environmental conservation in Rondônia. Revista Ambiente e Sociedade, Campinas, v.05, n.05, p.93-107, 1999.

PRATES, R. C. O desmatamento desigual na Amazônia brasileira: sua evolução, suas causas e conseqüências sobre o bem estar. 2008. 135p. Tese (Doutorado) - Universidade de São Paulo, USP, Piracicaba, 2008.

SANTOS, C. A Fronteira do Guaporé. Porto Velho: Edufro, 2001. 202 p.

SANTOS, M. Espaço e Sociedade. 2.ed. Petropolis: Vozes,1982. 152p.

SANTOS, R. A. O. História econômica da Amazônia (1800 - 1920). São Paulo: T. A. Queiroz, 1980. 374 p.

SÉRRE, A. A gestão Ambiental Urbana na Amazônia: Um investimento de longo prazo da política pública. In: IV Encontro Nacional da ECOECO, 2001, Belém. Resumos. p.14.

TEIXEIRA, M. A. D.; FONSECA, D. R. História Regional: Rondônia. 3. ed. Porto Velho: Rondoniana, 2002. 232 p.

TOCANTINS, L. "Amazônia, Natureza, Homem e Tempo". Rio de Janeiro: Conquista, 1960. 240p.

Recebido para publicação em janeiro de 2011

Aprovado para publicação em maio de 2011 